\title{
DEFINING PROCESS STRUCTURE FOR PROJECT RESOURCE ALLOCATION
}

\author{
Mihaela Carmen Grigore, Sorin Ionescu and Doina Marina Stefan \\ University Polytechnic of Bucharest - Faculty of Entrepreneurship, \\ Business Engineering and Management \\ Bucharest, Romania
}

\begin{abstract}
Resource allocation has become an activity with high criticality and impact on product delivery, going to transformation into a process involving multiple stakeholders.

The purpose of this paper is to present the results of a $\mathrm{PhD}$ research with defined resource allocation diagram, process and subprocesses, based on previous work results analysis and interpretation, having input from local project management community through online surveys and propose those for a larger input and implementation as process improvement in project management.

Availability of resources in projects has definitive impact on product delivery. Key function resources allocated to multiple projects within an organization create dependencies to all involved projects, therefore risks coming along to all involved products and organization's strategic targets.

Contribution of this paper is foreseen as important to large project management-oriented individuals and organizations, providing a guidance and good practice for designing and implementing improved processes with focus on resource allocation.
\end{abstract}

\section{KEYWORDS}

Resource Allocation, Process, Subprocess, Diagram, Product

\section{INTRODUCTION}

Projects can be considered as a set of activities that must be completed in accordance to specific objectives which involves the utilization of a company's resources (Alias et al, 2014).

Project development is done through project management processes.

A process may be defined as a sequence of activities completed by participants with the scope of meeting targets and deliver increased value to an organization (Ionescu, 2017).

Product delivery is done with the participation of all compartments, each compartment having its own contribution. As each product has its own value, it results that each activity contributes to obtain value (Ionescu, 2017).

Project focused organizations have defined and implemented processes around mostly of the project management areas. Thus, in a multicultural large program environment, project resource allocation has become a great challenge to program/project managers and product owners, dedicated processes for resource allocation becoming mandatory for program/project success.

Resource allocation has become an activity with high criticality and impact on product delivery, going to transformation into a process involving multiple stakeholders.

The purpose of this paper is to present the results of a $\mathrm{PhD}$ research with defined resource allocation diagram, process and subprocesses, based on previous work results analysis and interpretation, having input from local project management community through online surveys and propose those for a larger input and implementation as process improvement in project management. 
Availability of resources in projects has definitive impact on product delivery. Key function resources allocated to multiple projects within an organization create dependencies to all involved projects, therefore risks coming along to all involved products and organization's strategic targets.

Contribution of this paper is foreseen as important to large project management-oriented individuals and organizations, providing a guidance and good practice for designing and implementing improved processes with focus on resource allocation.

\section{DEFINING PROCESS STRUCTURE}

From a Project Management perspective, critical success factors, are characteristics, conditions or variables, that can have a significant impact on the success of the project when properly sustained, maintained or managed (Alias et al, 2014).

Organizational and project success factors are influenced by the inside and outside perception as well.

Stakeholders' perception defines the organizational image.

Various assumptions over an organizational image have been approached and brought into attention by Richard W. Scott that contributes to understanding the essential organizational characteristics. The system rationale: the organizations are collectively focused on tracking certain specific targets and high formalized structures (Scott, 1998).

Managing a multi-project environment requires a different method than managing a single project. The main challenge of managing a multi-project environment is the allocation of the scarce human resources over the projects in execution (Ponsteen and Kusters, 2014). That results in a need of process definition for resource allocation.

Project resource allocation represent a challenge to all project managers, especially in the IT Software Development area, where project outcome is not very well known in most cases.

A resource problem in one project can easily create problems in many other projects. Therefore, solving the resource allocation problem is crucial for the performance of the organization (Ponsteen and Kusters, 2014).

Allocation of resources to multiple projects creates dependencies between projects or even programs. The need of designing and implementing a resource allocation process, shared and agreed with all involved stakeholders has become mandatory in large project-oriented organizations to ensure projects success.

The process represents a sequence of activities that generates a desired outcome (Ionescu, 2017).

In order to propose best practices in resource allocation, as process improvement in project management, a diagram for resource allocation process has been developed, based on research analysis and surveys results interpretation.

Following our research results, we have designed the resource allocation process diagram, which in detail, may be explained as follows:

The resource allocation process is managed by the program manager together with the involved project managers. The current year book of work is decomposed by the program manager in projects. The project managers build the work breakdown structure for those projects they are responsible for. Based on the detailed work breakdown structures, the resource estimations are done, as well as definition of roles and needed skills within each project. Depending on determined resource availability, the program manager consulting project managers will decide the allocation of resources to projects. For those cases where lack of resources for project completion is identified, the program manager consulting the sponsor/ product owner will step to prioritizing projects and/or project activities and/or asking for new positions permanent/ temporary to be created/ approved, so that resource allocation may be completed. Resource allocation percentage is defined within same process. 
1:

The resource allocation process diagram proposed for guidance and implementation is presented in Figure

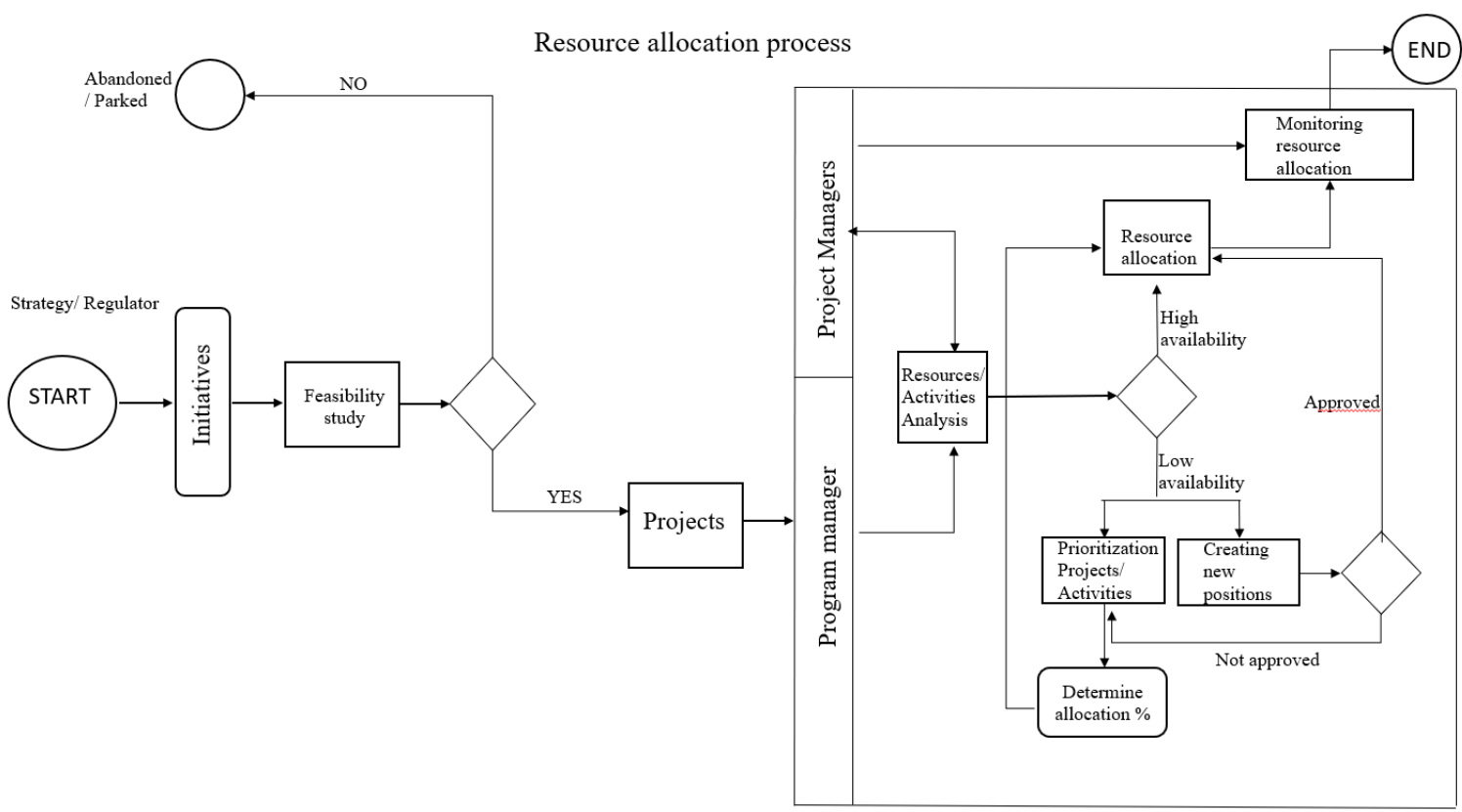

Figure 1. Resource allocation process diagram

The proposed resource allocation process is composed of subprocesses. A subprocess is represented by a sequence of activities that ensure the completion of a process.

The subprocesses of the resource allocation process are defined as follows:

1. Resources/ Activities Analysis

2. Prioritization Projects/ Activities

3. Creating New Positions

4. Resource Allocation

5. Monitoring Resource Allocation

The detailed list of subprocesses activities are presented in Figures 2-6.

1. Resources/ Activities Analysis: 


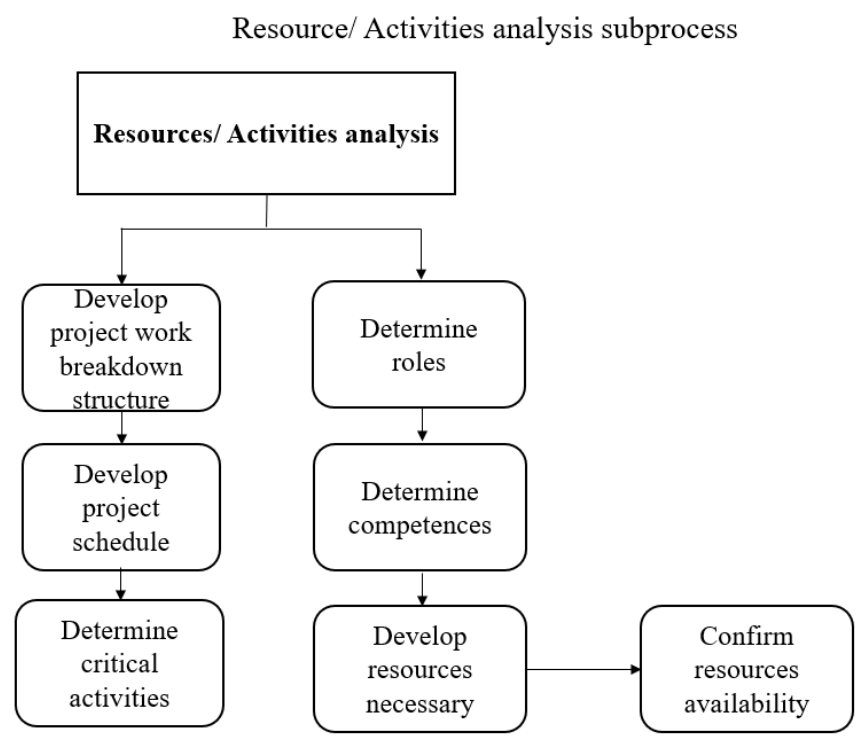

Figure 2. Resources/ Activities analysis subprocess diagram

2. Prioritization Projects/Activities

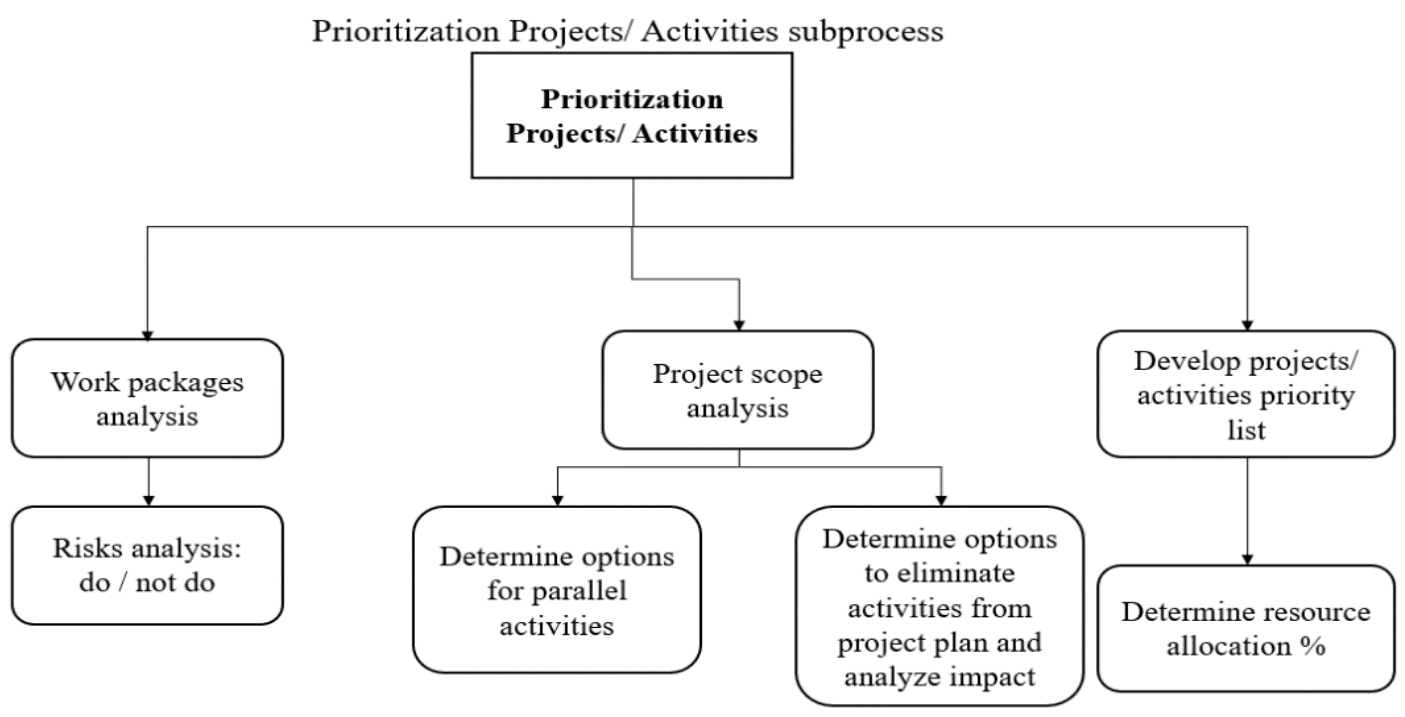

Figure 3. Prioritization Projects/ Activities subprocess diagram 
3. Creating New Positions

Creating new positions subprocess

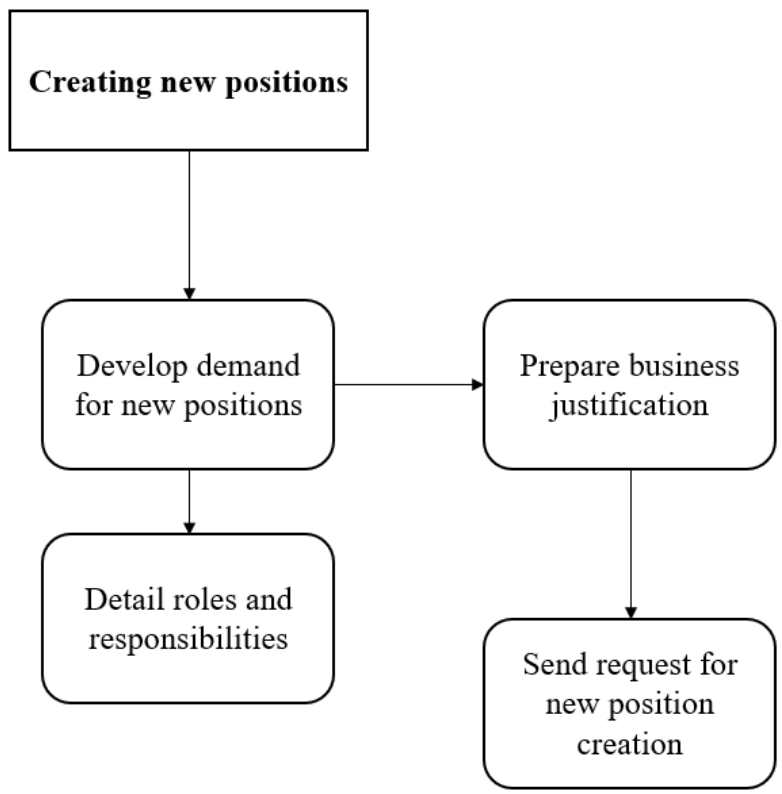

Figure 4. Creating new positions subprocess diagram

4. Resource Allocation

Resource allocation subprocess

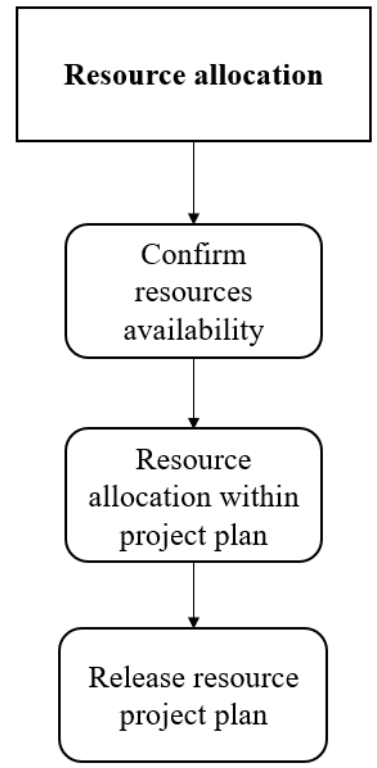

Figure 5. Resource allocation subprocess diagram 
5. Monitoring Resource Allocation

Monitoring resource allocation subprocess

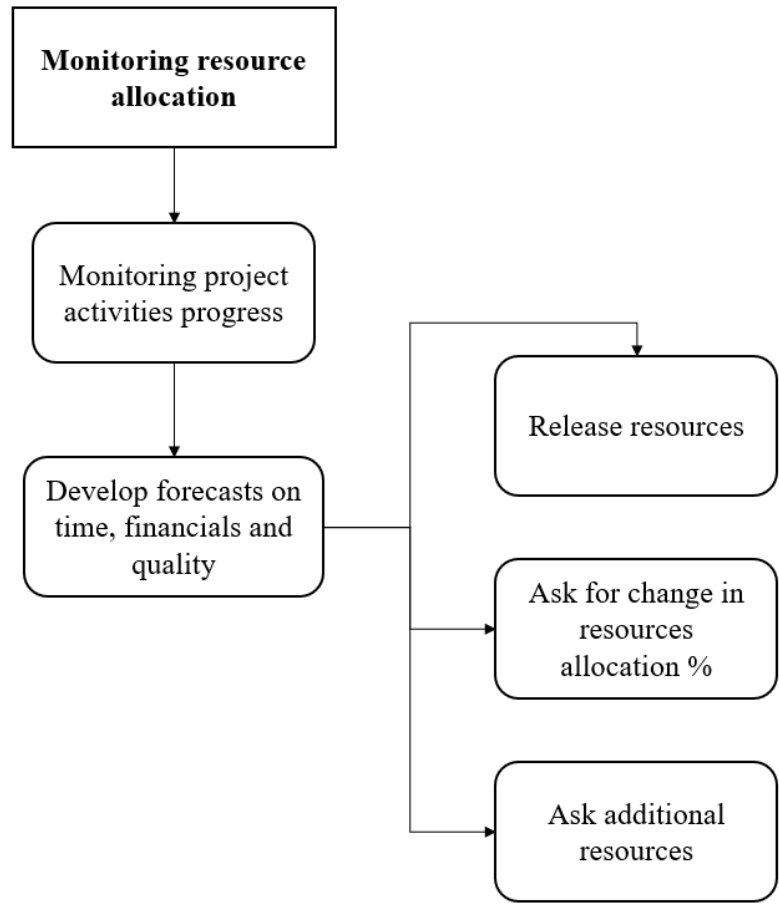

Figure 6. Monitoring resource allocation subprocess diagram

The resource allocation process incorporates in its flow the activities identified through $\mathrm{PhD}$ research as being critical for project delivery. According to the research study and author's recommendations, criticality of activities is extended to those activities with direct impact on delivery, highlighting the risk of not having product acceptance from the product owner in case these activities are missing from the project plan and not considered during project execution, monitoring and control phases.

The developed process is intended to be proposed as best practice for project management process improvement.

A best practice is a proven process that delivers measurable improvements in efficiency and/or effectiveness.

\section{CONCLUSION}

High complexity and focus on project development worldwide have brought even more into the attention of practitioners and researchers the need of designing a context to resource availability for product delivery.

Efficient planning is crucial for project success and it involves planning of those activities required in order to obtain the scope of the project. Criticality of the activities is widely discussed in the context of their existence on the critical path of the project. Author's research points out the need and justification to extend the rationale of activities criticality to those activities whose absence from the project plan would have direct impact on deliverables of the project, creating a high risk of non-acceptance of the product.

The advantage of introducing the critical activities illustrated in the resource allocation process flow is to significantly reduce the risk of product non acceptance. In addition to this, the implementation of a resource allocation process adapted to project's scope and utilized project management methodology ensures transparency for main stakeholders within complex programs/ portfolios with shared key resources and meeting project milestones. 
The resource allocation process including subprocesses may be applied in Waterfall based developed projects as well as Agile fashioned.

Possible limitation would appear in case of large portfolios with teams located in several world regions, communication between project managers utilizing shared resources being essential for the successful implementation of the resource allocation process.

The data on resource allocation process presented in this paper will be considered for further investigation in order to help define the state of the art within the $\mathrm{PhD}$ research mentioned in the Acknowledgement section and will stay as basis of development for a Good Practices in resource allocation for project monitoring framework, with focus on IT Software Development projects.

\section{ACKNOWLEDGEMENT}

This paper has been developed as part of an ongoing PhD research at the Polytechnic University of Bucharest, related to resource allocation and quality assurance in project monitoring. The title of the thesis is "Development of modules for resource allocation and quality assurance in project monitoring".

\section{REFERENCES}

Alias, Z., et al, 2012, Project Management towards Best Practice, ASIA Pacific International Conference on Environment Behavior Studies, Giza, Egypt, pp. 108-120.

Alias, Z., et al, 2014, Determining Critical Success Factors of Project Management practice: A conceptual framework, AMER International Conference on Quality of Life, Sabah, Malaysia, pp. 61-69.

Ionescu, S.C., 2017, Introduction in Management, POLITEHNICA PRESS, Bucharest, Romania.

Ponsteen, A. and Kusters, R.J., 2014, Classification of Human and Automated Resource Allocation Approaches in Multi-Project Management, $28^{\text {th }}$ IPMA World Congress, Rotterdam, The Nederlands, pp. 165-173.

Scott, W. Richard, 1998, Organizations: rational, natural and open systems, Canadian Journal of Sociology/ Cahiers canadiens de sociologie, pp. 29(1). 